\title{
Leishmania infantum Exoproducts Inhibit Human Invariant NKT Cell Expansion and Activation
}

\section{OPEN ACCESS}

Edited by:

Alexandre Morrot,

Federal University of Rio

de Janeiro, Brazil

Reviewed by:

Luc Van Kaer,

Vanderbilt University,

United States

Graham Robert Leggatt,

The University of Queensland,

Australia

*Correspondence:

Maria Leite-de-Moraes

maria.leite-de-moraes@

parisdescartes.fr;

Anabela Cordeiro-da-Silva

cordeiro@ibmc.up.pt

tThese authors have contributed equally to this work.

Specialty section:

This article was submitted to Microbial Immunology,

a section of the journal

Frontiers in Immunology

Received: 27 April 2017 Accepted: 01 June 2017

Published: 19 June 2017

Citation:

Belo R, Santarém N, Pereira C,

Pérez-Cabezas B, Macedo $F$, Leite-de-Moraes $M$ and Cordeiro-daSilva A (2017) Leishmania infantum Exoproducts Inhibit Human Invariant NKT Cell Expansion and Activation.

Front. Immunol. 8:710.

doi: 10.3389/fimmu.2017.00710

\author{
Renata Belo ${ }^{1,2,3}$, Nuno Santarém ${ }^{1}$, Cátia Pereira ${ }^{4}$, Begoña Pérez-Cabezas ${ }^{1}$, \\ Fátima Macedo ${ }^{4,5}$, Maria Leite-de-Moraes ${ }^{2,3 *+}$ and Anabela Cordeiro-da-Silva ${ }^{1,6 * \dagger}$
}

'Parasite Disease Group, Institute for Molecular and Cell Biology (IBMC), Institute for Investigation and Innovation in Health (i3S), Porto, Portugal, ' 2 Laboratory of Immunoregulation and Immunopathology, Institut Necker-Enfants Malades, CNRS UMR 8253 and INSERM UMR 1151, Paris, France, ${ }^{3}$ Université Paris Descartes Sorbonne Paris Cité, Paris, France, ${ }^{4}$ Cell Activation and Gene Expression, Institute for Molecular and Cell Biology (IBMC), Institute for Investigation and Innovation in Health (i3S), Porto, Portugal, ${ }^{5}$ Department of Medical Science, Aveiro University, Aveiro, Portugal, ${ }^{6}$ Faculty of Pharmacy, Department of Biological Sciences, University of Porto, Porto, Portugal

Leishmania infantum is one of the major parasite species associated with visceral leishmaniasis, a severe form of the disease that can become lethal if untreated. This obligate intracellular parasite has developed diverse strategies to escape the host immune response, such as exoproducts (Exo) carrying a wide range of molecules, including parasite virulence factors, which are potentially implicated in early stages of infection. Herein, we report that $L$. infantum Exo and its two fractions composed of extracellular vesicles (EVs) and vesicle-depleted-exoproducts (VDEs) inhibit human peripheral blood invariant natural killer T (iNKT) cell expansion in response to their specific ligand, the glycolipid $\alpha$-GalactosylCeramide ( $\alpha$-GalCer), as well as their capacity to promptly produce IL-4 and IFN $\gamma$. Using plate-bound CD1d and $\alpha$-GalCer, we found that Exo, EV, and VDE fractions reduced iNKT cell activation in a dose-dependent manner, suggesting that they prevented $\alpha$-GalCer presentation by CD1d molecules. This direct effect on CD1d was confirmed by the observation that CD1d: $\alpha$-GalCer complex formation was impaired in the presence of Exo, EV, and VDE fractions. Furthermore, lipid extracts from the three compounds mimicked the inhibition of iNKT cell activation. These lipid components of $L$. infantum exoproducts, including EV and VDE fractions, might compete for CD1-binding sites, thus blocking iNKT cell activation. Overall, our results provide evidence for a novel strategy through which $L$. infantum can evade immune responses of mammalian host cells by preventing iNKT Iymphocytes from recognizing glycolipids in a TCR-dependent manner.

\section{Keywords: Leishmania, NKT cells, exoproducts, peripheral blood mononuclear cell, parasite escape}

\section{INTRODUCTION}

Leishmaniasis is a neglected tropical disease caused by parasites of the genus Leishmania. These parasites have a complex digenetic life cycle, adopting an extracellular, flagellated, and motile form (promastigotes) in the insect vector and an intracellular, non-motile form (amastigotes) in the vertebrate host (1-3). Promastigotes, inside the mammalian host, infect phagocytic cells where they rapidly transform into the amastigote form that replicates, ruptures the host cell, and spreads the infection. The clinical manifestations of the disease vary with parasite species and host immune 
responses, ranging from subclinical infection, and self-healing lesions to chronic symptoms that can ultimately lead to death (1-3). A successful infection depends on the different mechanisms of evasion developed by the parasite, enabling it to subvert the immune responses and to persist in the mammalian host $(4,5)$. The main strategy consists in inducing antigenic diversion, which impairs both innate and adaptive immune responses $(4,5)$.

Recent research on new mechanisms of parasite escape has emphasized the capacity of Leishmania to release exoproducts (Exo) (6-8). We have shown that Exo can be separated into two fractions, namely vesicle-depleted-exoproducts (VDEs) and extracellular vesicles (EVs) (6). The latter, which are released into the extracellular environment by many types of eukaryotic and prokaryotic cells, are currently the focus of much interest. They are delimited by a lipid bilayer including specific proteins, lipids, and mRNA, depending on their cellular origin (9-12). These vesicles have been extensively studied because of their capacity to mediate intercellular communication that does not require cell-to-cell contact (9-12). In the context of infections by parasites, such as L. infantum, the influence of total Exo, EV, and VDE fractions on mammalian host immune responses is still a matter of debate.

Invariant natural killer T (iNKT) cells form a distinct population of $\mathrm{T}$ lymphocytes with innate-like properties. They express an invariant TCR $\alpha$-chain (V $\alpha 14$-J $\alpha 18$ in mice and $\mathrm{V} \alpha 24$-J $\alpha 18$ in humans) associated with a restricted set of $\mathrm{V} \beta$ chains, including $\mathrm{V} \beta 8, \mathrm{~V} \beta 7$, and $\mathrm{V} \beta 2$ in mice and $\mathrm{V} \beta 11$ in humans. Unlike conventional $\mathrm{T}$ cells, which recognize peptide antigens in the context of MHC class I or II molecules, iNKT cells are restricted by glycolipid antigens presented by the non-polymorphic MHC class I-like molecule CD1d (13-16). The $\alpha$-galactosylceramide $(\alpha$-GalCer) is a potent and specific antigen that is frequently used in the study of iNKT cells for stimulation and identification by the use of $\alpha$-GalCer-loaded CD1d tetramers (17). The innatelike character of iNKT cells is revealed by their ability to rapidly respond to stimulation by producing a wide range of cytokines, such as IFN $\gamma$, IL-4, IL-17, IL-10, and IL-13, which endows these cells with an exceptional immunomodulatory potential (18-21). iNKT cells are implicated in a number of immune responses including autoimmunity, tumor immunology, and immunity against viral, bacterial, fungal, and parasitic pathogens, namely Leishmania (22-29). Additionally, iNKT cells play a major role in patrolling the body and in mounting distinct immune responses to infections $(30,31)$.

Here, we found that exposure to Exo, EV, and VDE fractions led to the inhibition of human peripheral blood iNKT cell expansion and cytokine production in response to $\alpha$-GalCer. Starting from this finding, we set out to examine the mechanisms through which this inhibition occurred and attempted to identify the molecules involved as well as their mode of action.

\section{MATERIALS AND METHODS}

\section{Parasites}

A cloned line of virulent Leishmania infantum (MHOM/MA/67/ ITMAP-263) was maintained by weekly sub-passages at $26^{\circ} \mathrm{C}$ in RPMI 1640 medium supplemented with $10 \%$ heat-inactivated fetal bovine serum (FBS), $100 \mathrm{U} / \mathrm{ml}$ penicillin, $100 \mathrm{mg} / \mathrm{ml}$ streptomycin, and $20 \mathrm{mM}$ HEPES (all from Lonza). Only promastigotes from up to 10 passages were used in the experiments. Before recovery of extracellular material, parasites were transferred to cRPMI, a protein-deprived medium composed of RPMI base supplemented with SDM base and hemin, which was previously optimized for exosome studies (32). The starting inoculum for all cultures was $1 \times 10^{6}$ parasites $/ \mathrm{ml}$.

\section{Preparation of $L$. infantum Extracellular}

Promastigotes were grown in cRPMI for 4 days as previously described (32). Parasites were removed from culture supernatant by centrifugation and filtration through a $0.4 \mu \mathrm{m}$ filter. To recover the total exoproducts, the filtrated supernatant was concentrated in a centrifugal filter unit with a membrane nominal molecular weight limit (NMWL) of $3 \mathrm{kDa}$. To isolate $\mathrm{EV}$, the filtrated supernatant was concentrated in a centrifugal filter unit with a NMWL of $100 \mathrm{kDa}$ and ultracentrifuged overnight at $100,000 \mathrm{~g}$, $4^{\circ} \mathrm{C}$. The volume that passed through was further concentrated in a centrifugal filter unit with a NMWL of $3 \mathrm{kDa}$, in order to obtain VDE. These three preparations were dialyzed twice against PBS using the respective filter devices and resuspended in PBS. Finally, each preparation was passed through a $0.2 \mu \mathrm{m}$ filter. Note that $1 \times$ Exo, EV, or VDE designates products released from $1 \times 10^{7}$ parasites per microliters (Figure $S 1$ in Supplementary Material).

We used EV isolated from the human pancreas adenocarcinoma-derived BxPC-3 cell line as a negative control (33) (hereafter termed heterologous EV or hEV). Heterologous EVs were prepared following the ExoQuick-TC ${ }^{\mathrm{TM}}$ instruction manual. Briefly, the supernatant of the BxPC-3 cell line, previously cultured in RPMI medium with exosome-free FBS, was collected and centrifuged $15 \mathrm{~min}$ at 3,000 $\mathrm{g}$ to remove cells and debris. The supernatant was then incubated overnight with the ExoQuick-TC ${ }^{\mathrm{TM}}$ precipitation solution at $4^{\circ} \mathrm{C}$. The preparation was centrifuged at 1,500 $\mathrm{g}$ for $30 \mathrm{~min}$., supernatant was discarded, and the hEVs were resuspended in PBS.

\section{Biological Samples}

Peripheral blood mononuclear cells were collected from healthy donors at the Etablissement Français du Sang (EFS), Paris, France, and at the Immuno-haemotherapy Department of Hospital de São João, Porto, Portugal. Experiments were performed in accordance with the Helsinki Declaration, with informed consent received from each donor and managed by each institution. PBMCs were isolated by density-gradient centrifugation (Ficoll-Paque PLUS, GE Healthcare or Histopaque-1077, Sigma). C57BL/6J mice used for the preparation of bone marrow-derived dendritic cells (BM-DCs) were maintained in the animal facility at the Instituto de Biologia Molecular e Celular (IBMC, Porto, Portugal). Animals were euthanized in accordance with the IBMC.INEB Animal Ethics Committees and the Portuguese National Authorities for Animal Health guidelines (directive 2010/63/EU).

\section{Human iNKT Cell Expansion}

Peripheral blood mononuclear cells were cultured in 24-well plates at a density of $10^{6}$ cells per well in RPMI 1640 medium 
containing antibiotics, 10\% heat-inactivated FBS, $200 \mathrm{mM}$ glutamine, and $10 \mathrm{mM}$ HEPES (all from Invitrogen or Lonza) with $100 \mathrm{ng} / \mathrm{ml} \alpha$-GalCer (Alexis-Coger SA), as previously described $(18,19)$. When indicated, L. infantum Exo, EV, VDE, and hEV were added at the onset of culture. Twenty-four hours later, rhIL-2 (purchased from R\&D or kindly provided by the National Cancer Institute) was added. After 8-12 days, cells were harvested, extensively washed, and counted using trypan blue dye exclusion for dead cells. Cells were further stained and analyzed by flow cytometry.

\section{Surface and Intracellular Staining}

Fresh or cultured PBMCs were stained and analyzed by flow cytometry as previously described $(18,19)$. Surface staining was performed in PBS buffer containing 2\% FBS and $0.01 \% \mathrm{NaN} 3$, using PBS57-loaded-CD1d-tetramers (from the National Institutes of Health Tetramer Core Facility) (in all Figures stated as CD1d-tetramers), and the following directly conjugated anti-human monoclonal antibodies: PerCP-Cy5.5labeled anti-CD3 (OKT3), PE-Cy7-labeled anti-CD4 (RPA-T4), and antigen-presenting cell (APC)-labeled-anti-CD8 (RPA-T8) (eBioscience).

For intracellular cytokine staining, CD1d-transfected C1R cells were incubated with $\alpha$-GalCer alone or in the presence of L. infantum Exo, EV, and VDE. Human iNKT cell lines and $10 \mu \mathrm{g} / \mathrm{ml}$ brefeldin A (Sigma-Aldrich) were added $2 \mathrm{~h}$ later. After a 5-h incubation, cells were harvested and washed before fixation with $4 \%$ paraformaldehyde and permeabilization using $1 \%$ saponin (Sigma-Aldrich). Cells were then stained with antiCD3, APC-labeled anti-IL-4 (8D4-8), and PE-Cy7-anti-IFN $\gamma$ (4S.B3) (eBioscience). Data were acquired on a FACS Canto II flow cytometer (BD Biosciences) and analyzed with FlowJo software (10.2).

\section{Detection of CD1d: $\alpha$-GalCer Complex Formation}

Dendritic cells (DCs) were derived from bone marrow (BM) precursors as previously described (34). In brief, BM precursors recovered by flushing femurs and tibias from the hind legs of C57BL/6J mice were suspended in RPMI supplemented with $10 \%$ heat-inactivated FBS, $100 \mathrm{U} / \mathrm{ml}$ penicillin, $100 \mu \mathrm{g} / \mathrm{ml}$ streptomycin, and $10 \mathrm{mM}$ HEPES (all from Lonza), $50 \mu \mathrm{M}$ 2-Mercaptoethanol (Sigma Chemical), and 10\% of J558 cell line supernatant containing GM-CSF (J558-GM-CSF) and cultured at $37^{\circ} \mathrm{C}$ with $5 \% \mathrm{CO}_{2}$ in $\mathrm{T} 75$ culture flasks with a vented cap. At day 3 , the same amount of supplemented medium was added to each flask. At day 6 and 8, half of the volume of each flask was recovered and centrifuged and the cell pellet was resuspended in the same amount of supplemented medium. At day 9, BM-DCs were harvested, washed, and cultured in RPMI 2\% FBS with $100 \mathrm{ng} / \mathrm{ml} \alpha$-GalCer and/or increasing doses $(1,10,20 \times)$ of L. infantum Exo, EV, or VDE for $4 \mathrm{~h}$. CD1d expression and formation of CD1d: $\alpha$-GalCer complexes on the surface of BM-DC was then determined by flow cytometry using the following mAbs: anti-mouse CD1d (51.1) (eBioscience) and anti-mouse CD1d: $\alpha$ GalCer (L363, Biolegend).

\section{Human iNKT-Cell Line Generation and Restimulation}

A polyclonal primary iNKT cell line was generated as described (35) according to a previously established protocol (36). In brief, PBMCs from healthy donors were cultured with $100 \mathrm{ng} / \mathrm{ml}$ of $\alpha$-GalCer (KRN7000) and $100 \mathrm{U} / \mathrm{ml}$ of IL-2 (R\&D Systems). After 11 days, CD1d-PBS57 tetramer ${ }^{+} \mathrm{CD}^{+}$cells were sorted using a FACSAria cell sorter (BD Biosciences). When cells stopped proliferating, $1 \mu \mathrm{g} / \mathrm{ml}$ of PHA (Thermo Fisher Scientific, Waltham, MA, USA) was added together with irradiated PBMC for restimulation.

\section{iNKT Cell Activation Assays}

Invariant natural killer $\mathrm{T}$ cell activation assays were performed using CD1d-transfected C1R cells as APCs or soluble mouse CD1d coated in 384-well plates.

For assays using APC, CD1d-transfected C1R cells were cultured for $4 \mathrm{~h}$ with 5 or $25 \mathrm{ng} / \mathrm{ml}$ of $\alpha$-GalCer alone or together with increasing doses $(1,10,20 \times)$ of L. infantum Exo, EV, or VDE. The human polyclonal primary iNKT cell line was then added and supernatants from this co-culture were harvest $40 \mathrm{~h}$ later and assayed for GM-CSF by ELISA using purified (BVD2-23B6) and biotinylated (BVD2-21C11) anti-GM-CSF mAbs (Biolegend). CD1d (NIH tetramer core facility) was immobilized on 384-well Maxisorp treated microplates (Nunc, Rochester, NY, USA). After overnight incubation at $37^{\circ} \mathrm{C}$, a mixture of 25 or $100 \mathrm{ng} / \mathrm{ml}$ $\alpha$-GalCer and L. infantum Exo, EV, VDE, or hEV was added for $24 \mathrm{~h}$. In some experiments, $\alpha$-GalCer $(25 \mathrm{ng} / \mathrm{ml})$ was added $8 \mathrm{~h}$ before or after Exo, VDE, or EV (20x). After extensive washing, the 24.8 iNKT cell hybridoma $(25,000 /$ well) was added for further $20 \mathrm{~h}$. Culture supernatants were recovered, and IL-2 concentrations were determined by ELISA using purified (JES6-1A12) and biotinylated (JES6-5H4) anti-IL-2 mAbs (Biolegend).

\section{Lipid Extraction and Quantification}

Total lipid content was isolated from Exo, EV, and VDE using the Bligh and Dyer method (37). The lower organic phase was dried under nitrogen at $40^{\circ} \mathrm{C}$ and samples were kept at $-20^{\circ} \mathrm{C}$ until quantification. Total lipid content of each sample was assessed by the sulpho-phospho-vanillin colorimetric assay. Lipid extracts were solubilized in chloroform and incubated at $90^{\circ} \mathrm{C}$ in a heater block until solvent evaporation. Increasing concentrations of cholesterol (Sigma-Aldrich) dissolved in chloroform were treated similarly and used as standard. Upon addition of $96 \%$ sulfuric acid samples were further incubated at $90^{\circ} \mathrm{C}$ for $20 \mathrm{~min}$ and then cooled at $4^{\circ} \mathrm{C}$ for $4 \mathrm{~min}$ followed by the addition of $0.2 \mathrm{mg} / \mathrm{ml}$ vanillin in $17 \%$ phosphoric acid. The samples were then incubated at room temperature for $10 \mathrm{~min}$ and absorbance was measured at $540 \mathrm{~nm}$. They were finally re-dried and resuspended in RPMI 10\% FBS at appropriate concentrations to be used in functional assays. To facilitate solubilizing of lipid extracts in aqueous medium, the samples were dissolved first in a minimum volume of methanol.

\section{Statistical Analysis}

Values are expressed as the mean \pm SEM, and significant differences were determined using either Mann-Whitney 
non-parametric $t$-tests or ANOVA with 95\% confidence interval (GraphPad Prism 6). $p$-Values $(p<0.05)$ were considered significant. ${ }^{*} p<0.05,{ }^{* *} p<0.01,{ }^{* * *} p<0.001$.

\section{RESULTS}

\section{L. infantum Exoproducts Inhibit iNKT Cell Expansion}

Previous reports support a possible influence of iNKT cells on the outcome of experimental Leishmania infection $(38,39)$. However, there are only few data documenting their impact on the severity of the human pathology. Our expertise in preparing exoproducts as well as EV and VDE fractions (6), together with the human iNKT cell expansion protocol currently used in our laboratory $(18,19)$, enabled us to examine how L. infantum Exo affected the functional properties of these lymphocytes. iNKT cells were identified by their expression of CD3 and CD1d-tetramers loaded with PBS57 antigen ( $\alpha$-GalCer analog), as previously described $(18,19)$. PBMCs isolated from healthy donors were cultured with $\alpha$-GalCer alone or together with L. infantum Exo, EV, VDE, or heterologous EV (hEV) used as a negative control. Exo, as well as VDE and EV significantly impaired the expansion of iNKT cells (Figures 1A,B), while unrelated hEV had no effect (Figures 1A,B). L. infantum Exo, EV, and VDE targeted iNKT cells specifically since the frequency of conventional $\mathrm{CD}^{+}$and $\mathrm{CD}^{+} \mathrm{T}$ cells was not modified under these culture conditions (Figure 1C). Moreover, a possible toxicity of L. infantum extracts could be ruled out because total cell viability was not impaired (Figure 1D).

These findings clearly establish that L. infantum Exo, EV, and VDE fractions inhibit human peripheral blood iNKT cell expansion without affecting the frequency of conventional $\mathrm{CD} 4^{+}$and $\mathrm{CD}^{+} \mathrm{T}$ lymphocytes.

\section{L. infantum Exoproducts Impair Cytokine Production by iNKT Cells}

Invariant Natural Killer $\mathrm{T}$ cells are known for their ability to promptly and massively secrete cytokines when stimulated. To investigate how L. infantum Exo, EV, and VDE fractions affected this biological activity, we took advantage of a human polyclonal primary iNKT cell line instead of the heterogeneous in vitro expanded $\mathrm{PBMC}$ population. These cells were co-cultured with CD1d-transfected C1R cells loaded with $\alpha$-GalCer in the presence of increasing concentrations $(1,10$, and 20X) of $L$. infantum extracellular products. iNKT cell activation was assessed $40 \mathrm{~h}$ later. We validated that non-transfected C1R cells were unable to stimulate iNKT cells in these conditions (data not shown).

First, we ruled out a possible effect of Exo, EV, and VDE fractions per se on iNKT by evaluating the secretion of GM-CSF that did clearly not take place in response to these compounds (Figure S2 in Supplementary Material). However, all three exoproducts inhibited the activity induced by $\alpha$-GalCer in a dose-dependent manner (Figure 2A). The dose of $20 \times$ was the most effective for all compounds. Of note, a fivefold increase in $\alpha$-GalCer concentration reversed this inhibition, except for the dose of Exo 20× (Figure 2B). hEV had no significant effect on iNKT cell activation, whatever the dose (Figures 2A,B).

Next, we tested the ability of $L$. infantum exoproducts to modulate the production of cytokines by iNKT cells exposed for a short period to $\alpha$-GalCer. To this end, CD1d-transfected C1R cells were loaded for $2 \mathrm{~h}$ with $\alpha$-GalCer with or without Exo, $\mathrm{EV}$, and VDE fractions at the dose of $20 \times$. After extensive washings, iNKT cells were added to the culture for $5 \mathrm{~h}$. All three compounds inhibited IL- 4 and IFN $\gamma$ production in response to $\alpha$-GalCer $(5 \mathrm{ng} / \mathrm{ml})$, as shown in Figures 2C,E. The inhibition of IFN- $\gamma$ secretion by EV was less pronounced, while Exo and VDE remained significant throughout (Figures 2C,E). Higher doses of $\alpha$-GalCer $(25 \mathrm{ng} / \mathrm{ml})$ restored the production of IL- 4 by iNKT cells partially and that of IFN $\gamma$ completely (Figures 2D,E). hEV had no effect whatsoever whether $\alpha$-GalCer was used at 5 or $25 \mathrm{ng} / \mathrm{ml}$ (Figures 2C-E). Exo, $\mathrm{EV}$, and VDE fractions were unable to stimulate IFN $\gamma$ and IL-4 production by iNKT cells when incubated with CD1dtransfected C1R cells in the absence of $\alpha$-GalCer (Figure S3 in Supplementary Material).

Overall, these results suggest that Exo, EV, and VDE fractions might prevent optimal presentation of $\alpha$-GalCer by CD1d molecules either directly by competing for $\alpha$-GalCer-binding sites or indirectly by downregulating CD1d expression by transfected C1R cells.

\section{L. infantum Exo, EV, and VDE Fractions Exert a Direct Effect on CD1d Binding}

To asses whether L. infantum exoproducts inhibited $\alpha$-GalCer binding to CD1d molecules directly, we used a cell-free system of stimulation in which plate-bound mCD1d were loaded with $\alpha$-GalCer with or without increasing doses $(1,10$, and $20 \times)$ of Exo, EV, and VDE fractions. Following extensive washings, we added 24.8 iNKT hybridoma cells and assessed their activation by measuring IL-2 levels in supernatants. As shown in Figure 3A, IL-2 secretion in response to $25 \mathrm{ng} / \mathrm{ml} \alpha$-GalCer was significantly inhibited by all three fractions at doses of $10 \times$ and $20 \times$. Note that the inhibition was completely abrogated when $\alpha$-GalCer was added before (Figure 3B), and not after (Figure 3C), L. infantum Exo, EV, and VDE fractions. A similar reversal occurred when $\alpha$-GalCer was used at a fourfold higher dose (Figure 3D). In none of these conditions, did hEV modify IL-2 production by $\alpha$-GalCer-stimulated iNKT cells (Figures 3A,D), which was also not altered in response to $L$. infantum Exo, EV, and VDE fractions per se (Figure S4A in Supplementary Material).

To further strengthen these results, we used the $\mathrm{L} 363 \mathrm{mAb}$, which specifically recognizes CD1d: $\alpha$-GalCer complexes to quantify these interactions (40). We found a clear inhibition of complex formation in response to increasing doses of $L$. infantum Exo and VDE fractions (Figures 3E,F). Note that exoproducts did not alter the expression of CD1d by BM-DC, which further excludes an indirect effect via receptor downmodulation (Figure S4B in Supplementary Material). 


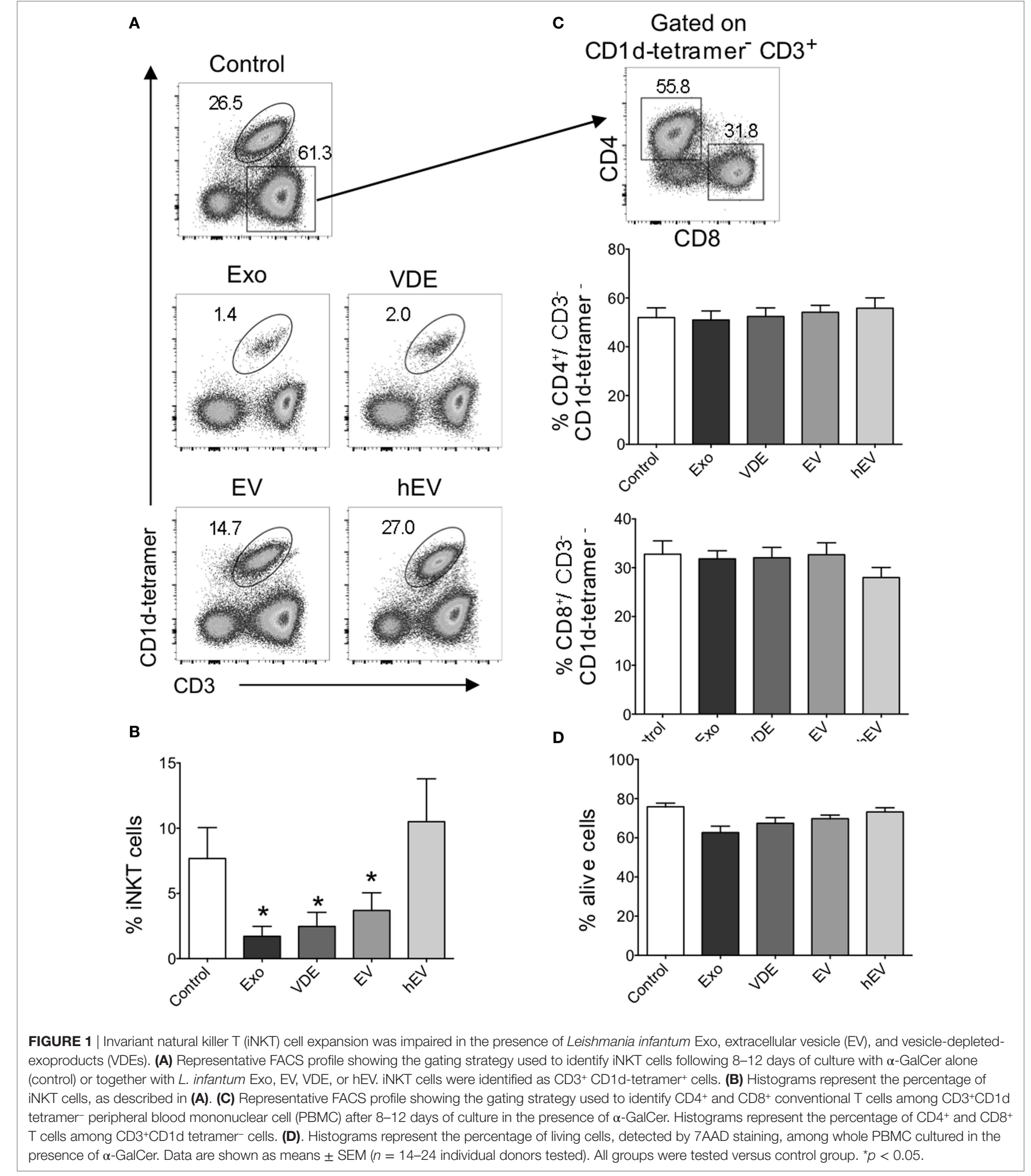

Gated on

Overall, these findings indicate that L. infantum Exo, EV, and VDE fractions directly block CD1d: $\alpha$-GalCer complex formation. Furthermore, experiments with plate-bound CD1d do not support an indirect mechanism involving CD1d downregulation.

\section{The Inhibition of iNKT Cell Activation by $L$. infantum Secreted Antigens Is Mediated through Lipids}

In the light of the above results, we addressed the question of the identity of the molecules that blocked CD1d: $\alpha$-GalCer 
complex formation. Knowing that glycolipids have been identified as the major CD1d ligands (15) and that the surface of L. infantum is covered by a glycocalix (41), it was tempting to
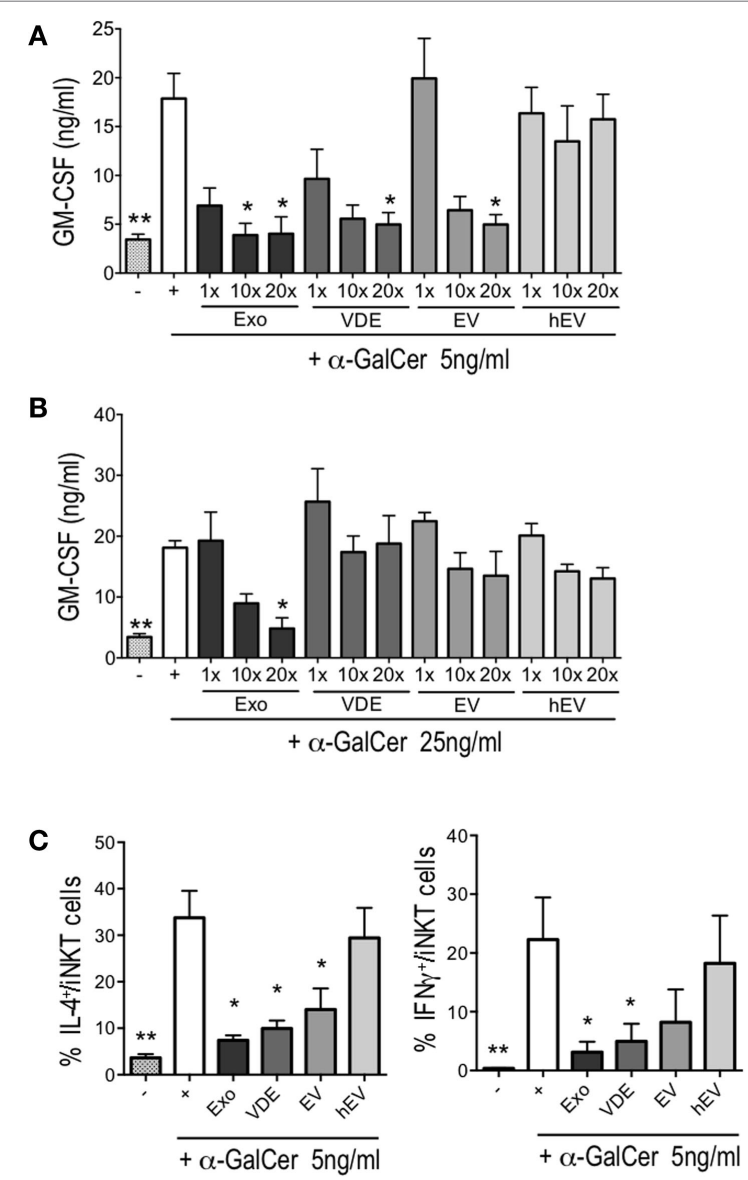

D

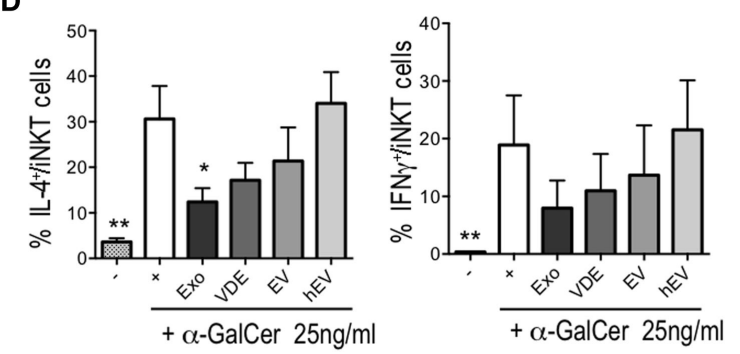

E
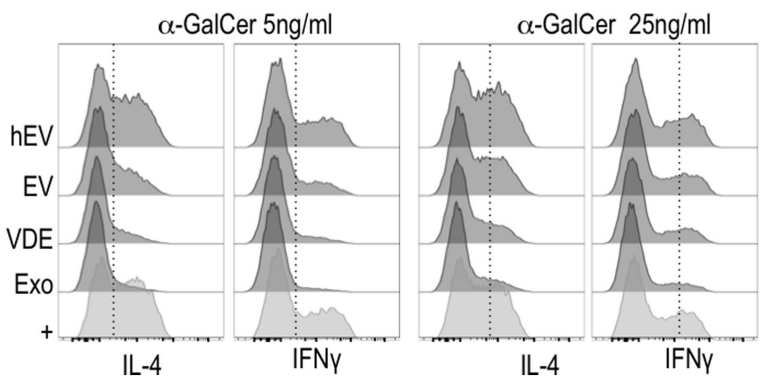

FIGURE 2 | Continued

\section{FIGURE 2 | Continued}

Leishmania infantum Exo, extracellular vesicle (EV), and vesicle-depletedexoproduct (VDE) altered invariant natural killer T (iNKT) cell function. The polyclonal human iNKT cell line was incubated with CD1d-transfected C1R cells alone (-) or previously loaded with $\alpha$-GalCer $5 \mathrm{ng} / \mathrm{ml}$ (A,C) or $25 \mathrm{ng} / \mathrm{ml}$ (B,D) with $(+)$ or without $L$. infantum Exo, EV, VDE, or hEV. iNKT cell activation was measured by assessing GM-CSF concentrations in culture supernatants $(\mathbf{A}, \mathbf{B})$ and by determining the percentage of $\mathrm{IL}-4^{+}$or $\mathrm{IFN} \gamma^{+}$cells among the iNKT cell line (C-E). Data show means \pm SEM and the results are representative of two to three independent experiments $(n=4)$. All groups were tested versus the positive $\alpha$-GalCer $(+)$ control group. ${ }^{*} p<0.05$,

${ }^{* \star} p<0.01$. (E) Representative FACS profile of the results presented at (C,D).

hypothesize that the lipids present in Exo, VE, and EV preparation were responsible for the inhibition of iNKT cell activation. Hence, we extracted total lipids from Exo, EV, and VDE fractions and tested them in the plate-bound CD1d assay. Figure $4 \mathrm{~A}$ shows that at high doses, they were all capable of inhibiting iNKT cell activation.

As a proof of concept, we tested whether the lipid extracts could also inhibit iNKT cell expansion from total PBMC, which was actually the case, as depicted in Figures 4B,C.

Collectively, these data demonstrate that lipids present in L. infantum Exo, EV, and VDE fractions account for the inhibition of iNKT cell activation induced by whole fractions.

\section{DISCUSSION}

Leishmaniasis remains a major public health issue because an effective human vaccine has not been developed so far. The most likely reason for this failure is that Leishmania spp. uses a variety of strategies to divert the immune system. Herein, we provide evidence for a new mechanism of evasion, which causes inhibition of TCR-dependent expansion and activation of human iNKT cells through release of exoproducts (Exo), EVs, and VDE by L. infantum promastigotes.

It is now widely acknowledged that Exo and its EV fraction are important players in the horizontal transfer of information between different cells, without direct contact. In this context, EVs could act as messengers capable of priming host cells to facilitate parasite infections (42). For instance, L. infantum promastigotes constitutively secrete EVs in the lumen of sandfly midgut, which contribute to the initial infective inoculum, being co-ingested with the parasite during the bite that initiates the pathology (43). Leishmania-derived EVs can ensure the transport of parasite virulence factors, such as GP63 proteins, to host cells. GP63 has previously been shown to interfere with host cell signaling pathways by inducing cleavage and activation of protein tyrosine phosphatases, downregulation of pro-inflammatory transcription factors and kinases, and decrease of NO production, thus weakening antimicrobial mechanisms of defense $(6,8,44)$. It has also been reported recently that Leishmania exosomes could become immunosuppressive by modulating monocyte cytokine responses to IFN $\gamma(45)$.

The impact of Leishmania Exo on immunoregulatory T lymphocytes, including iNKT cells, remains to be determined. The high degree of conservation between murine and human 

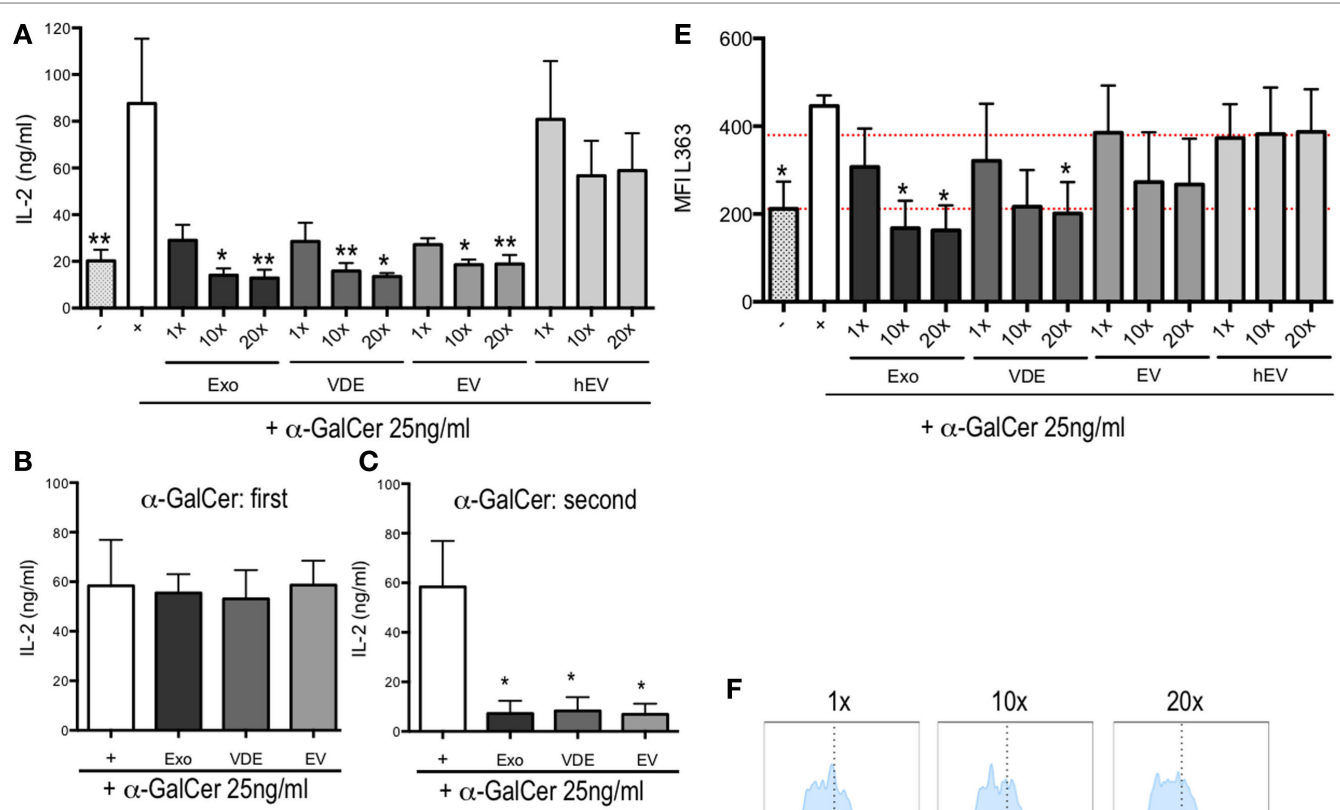

C

D
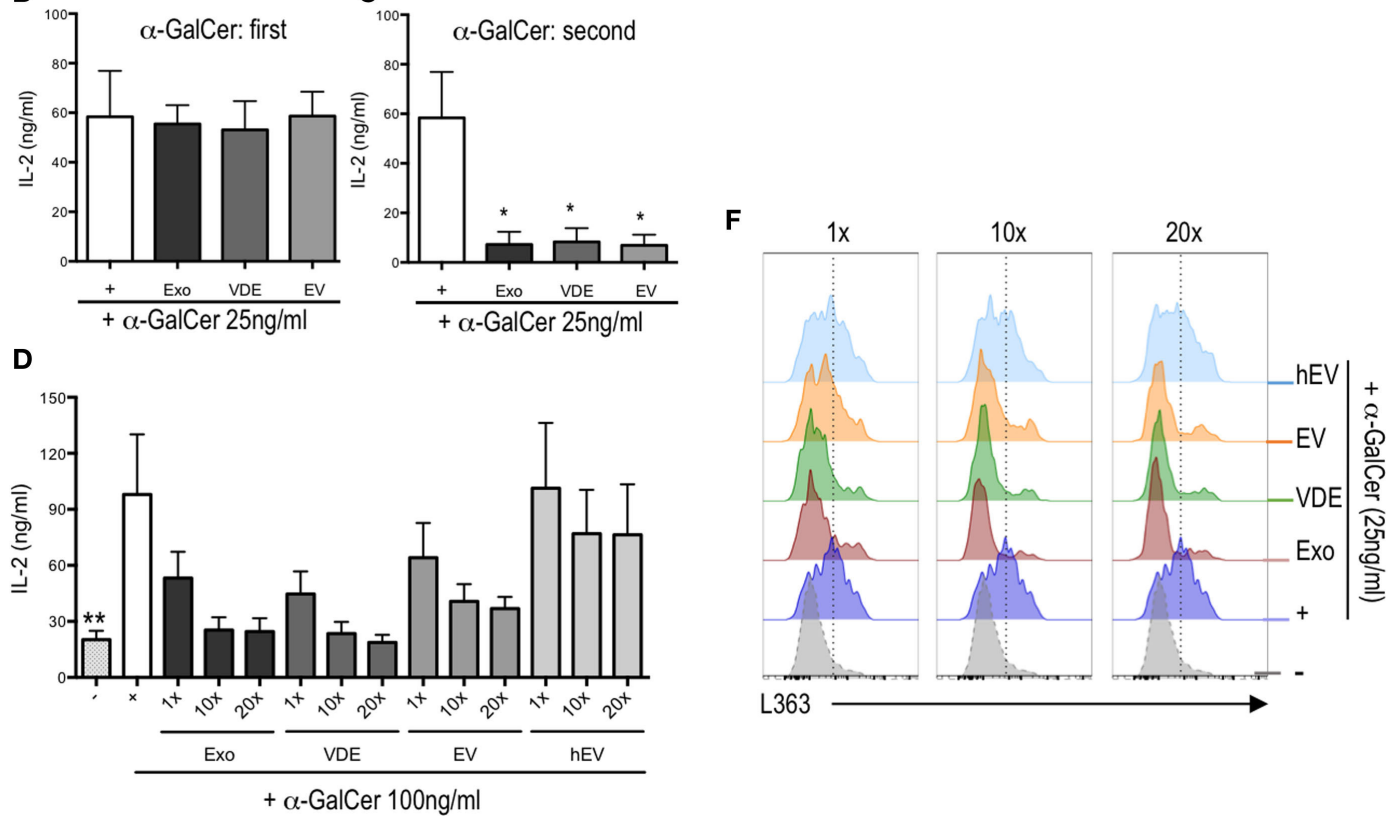

FIGURE 3 | Leishmania infantum Exo, extracellular vesicle (EV), and vesicle-depleted-exoproduct (VDE) inhibited invariant natural killer T (iNKT) cell activation by plate-bound $\alpha$-GalCer/CD1d complexes in a dose-dependent manner. Plate-bound mouse CD1d was loaded with a mixture of $\alpha$-GalCer $25 \mathrm{ng} / \mathrm{ml}$ (A,E,F) and $100 \mathrm{ng} / \mathrm{ml}$ (D) alone (+) or in the presence of $L$. infantum Exo, EV, VDE, or hEV at different doses. (B) Plate-bound mouse CD1d was loaded first with $\alpha$-GalCer at $25 \mathrm{ng} / \mathrm{ml}$. Eight hours later, L. infantum Exo, EV, VDE, or hEV (20x) was added. (C) Plate-bound mouse CD1d was loaded with L. infantum Exo, EV, VDE, or hEV (20x). Eight hours later, $25 \mathrm{ng} / \mathrm{ml}$ of $\alpha$-GalCer was added (second). After extensive washings, the $24.8 \mathrm{iNKT}$ cell hybridoma was added and supernatants were recovered $20 \mathrm{~h}$ later. Data are expressed as means \pm SEM of IL-2 levels detected in culture supernatants. Data are representative of two independent experiments $(n=4)$. All groups were tested versus positive $\alpha$-GalCer $(+)$ control group. ${ }^{*} p<0.05,{ }^{\star *} p<0.01$. (E) Histograms indicating MFI of L363 staining showing CD1d: $\alpha-$ GalCer complexes expressed by bone marrow-derived dendritic cells unstimulated (-) or previously incubated with $\alpha$-GalCer (+) or $\alpha$-GalCer plus $L$. infantum Exo, $\mathrm{EV}, \mathrm{VDE}$, or $\mathrm{hEV}$ at distinct doses. Data are expressed as means \pm SEM from three independent experiments. (F) Representative FACS profile showing the expression of L363 as described in (E). Data are representative of three independent experiments.

iNKT cell TCRs allows the same antigens presented by the non-polymorphic class-I-like molecule CD1d, such as $\alpha$-GalCer, to be recognized by both species, which strongly supports an important biological function. iNKT cells can be activated by two distinct TCR-dependent pathways, namely recognition of foreign (direct way) or self (indirect way) lipid agonists (46). The latter are induced during cell stress following injury or infection. Several microbes contain lipids that can be presented by CD1d molecules and directly activate iNKT cells. Examples are glycosphingolipids with $\alpha$-linked glucuronic or galacturonic acid in Sphingomonas species (47) and diacylglycerols with $\alpha$-linked glucosyl or galactosyl moieties in Borrelia burgdorferi (35) and Streptococcus pneumoniae (48). In addition to this pathogen, antigen-dependent mechanism of activation, microbes can also use indirect pathways to activate iNKT cells. For instance, a previous report (27) has shown that L. infantum-infected DCs can upregulate their CD1d expression, thus becoming a target efficiently recognized and killed by activated IFN $\gamma$-producing iNKT cells. Furthermore, Leishmania mexicana lipophosphoglycan (LPG) (49) stimulates DCs through an indirect pathway to produce IL-12 and IL-18 that, in turn, can induce IFN- $\gamma$ production by iNKT cells (50). Our findings indicate that L. infantum developed a means to evade protective immune responses by releasing Exo, EV, or VDE compounds to restrain the expansion and antigen activation of human iNKT cells.

Using plate-bound CD1d and L363 antibody to detect the formation of CD1d: $\alpha$-GalCer complexes, we established that L. infantum Exo, VDE, and EV impaired iNKT cell activation 
by preventing the binding of $\alpha$-GalCer to CD1d molecules. This effect was abolished at higher doses or when $\alpha$-GalCer was coated before the addition of $L$. infantum exoproducts revealing a potential competition between these compounds and $\alpha$-GalCer.

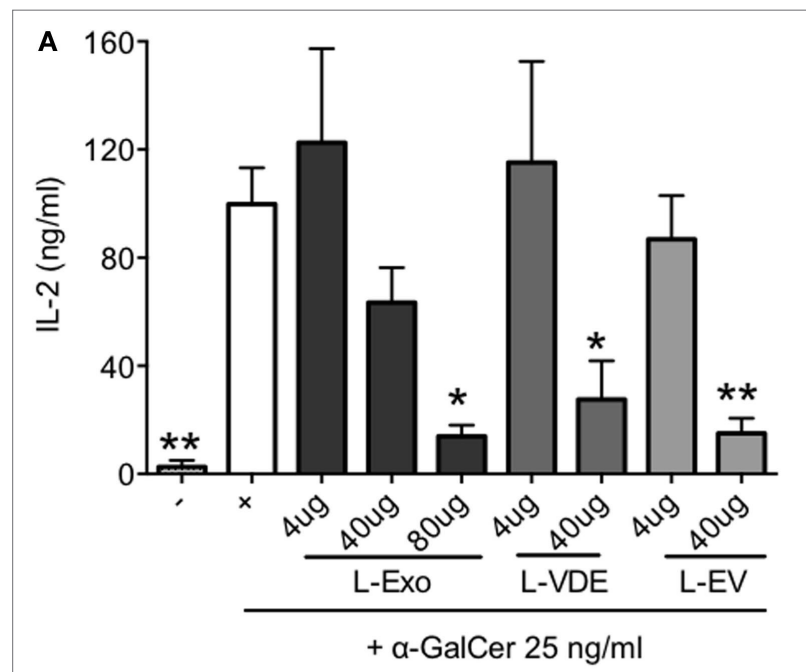

B

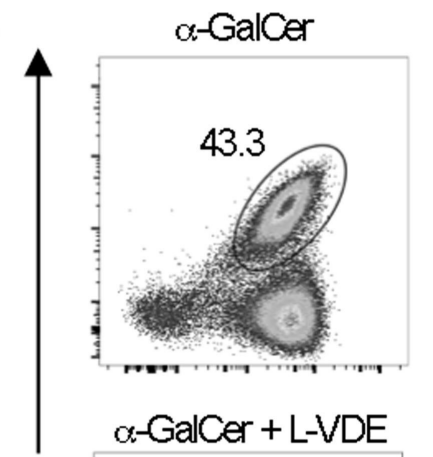

$\alpha-$ GalCer + L-Exo
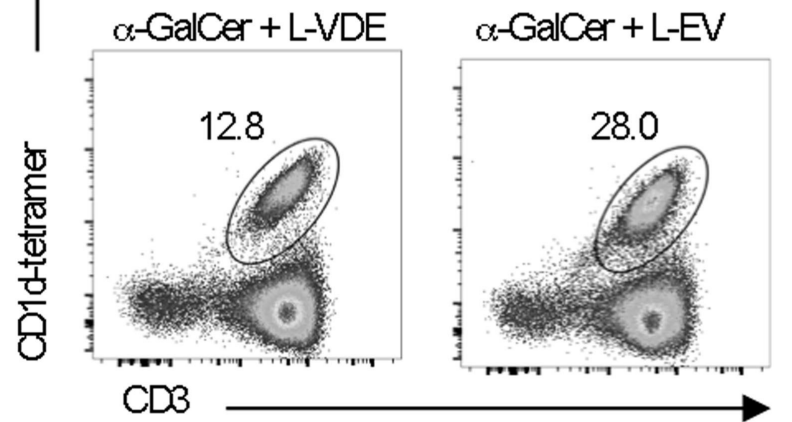

C

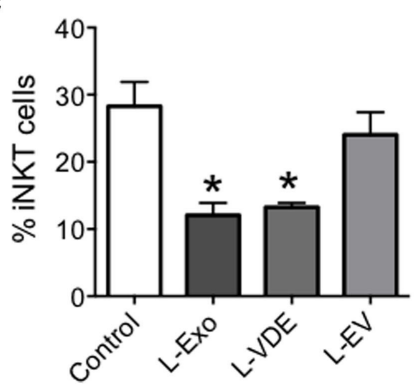

FIGURE 4 | Continued
FIGURE 4 | Continued

Lipids from Leishmania infantum Exo, extracellular vesicle (EV), and vesicle-depleted-exoproduct (VDE) mimicked the inhibition of invariant natural killer T (iNKT) cell activation. (A) Plate-bound mouse CD1d was loaded with $\alpha$-GalCer $(25 \mathrm{ng} / \mathrm{ml})$ solely or in the presence of distinct doses of lipid extracts from L. infantum Exo, EV, VDE. 24.8 iNKT cell hybridoma was added and IL-2 production in the supernatants was measured. Data are expressed as means \pm SEM of IL-2 concentrations in culture supernatants. Data are representative of two independent experiments $(n=4)$. All groups were tested versus the positive $\alpha$-GalCer (+) control group. ${ }^{*} p<0.05,{ }^{* *} p<0.01$.

(B) Representative FACS profile showing the percentage of iNKT cells obtained after culture of peripheral blood mononuclear cell with $\alpha$-GalCer in the presence of total lipid extracts from $L$. infantum Exo, EV, VDE.

(C) Histograms represent the percentage of iNKT cells, as described in (B). Data are expressed as means \pm SEM and they are representative of two to five independent experiments.

A previous report has shown that Leishmania donovani-infected macrophages and DCs failed to activate iNKT cells in response to $\alpha$-GalCer (51). The explanation provided was that L. donovani infection increased membrane fluidity and disrupted lipid rafts, which caused the relocation of CD1d molecules from lipid raft-rich to non-lipid raft regions, thus impairing antigen presentation to iNKT cells (51). Herein, we did not observe significant modifications in the expression of CD1d molecules by BM-DC incubated with Exo, EV, or VDE fractions (Figure S4 in Supplementary Material) indicating that these L. infantum compounds might use other means to impair CD1ddependent iNKT cell activation. A similar mechanism leading to the inhibition of iNKT cell activation was also observed with Globotriaosylceramide (Gb3), a glycosphingolipid that accumulates in patients affected by the Fabry disease, a lysosomal storage disorder $(52,53)$.

It is important to note that lipids extracted from Exo, VDE, and EV mimicked the inhibition of iNKT cell activation induced by the whole fractions. According to previous studies, two main glycocalyx components of $L$. donovani, LPG, and glycoinositolphospholipids (GIPLs), could be presented by CD1d molecules and activate iNKT cells $(39,51,54)$. Similar to our findings, LPG and GIPLs could compete with $\alpha$-GalCer for binding to CD1d molecules (39). L. donovani LPG induced CD1ddependent IFN $\gamma$ production by iNKT cells (39), in contrast with our findings that revealed no IFN $\gamma$, IL-4, or IL-2 production by iNKT cells stimulated with $L$. infantum Exo, VDE, and EV pulsed BM-DC (Figures S3 and S4 in Supplementary Material). The authors hypothesized (39) that iNKT cell activation by $L$. donovani LPG could contribute significantly to resistance in visceral leishmaniasis. We propose that L. infantum Exo, VDE, and EV fractions facilitate parasite evasion by impairing iNKT cell proliferation and activation. A possible explanation for these differences is that Leishmania LPG and GIPLs present an important polymorphism between the species (55). Another possibility is that molecules other than LPG and GIPLs are responsible for the effect we observed. Consequently, additional studies are required to better characterize the major lipid(s) implicated in this inhibitory effect and determine their molecular mechanism of action. It is possible that L. infantum lipids compete with the $\alpha$-GalCer for the same position within the CD1d binding groove. 
In this case, they would behave like iNKT cell antagonists since they did not induce cytokine production by iNKT cells. Our results exclude the possibility that parasite products interact with $\alpha$-GalCer itself to prevent its binding to CD1d since the inhibition of iNKT cells was maintained when plate-bound CD1d were first incubated with Exo, EV, and VDE, washed, and then incubated with $\alpha$-GalCer. Alternatively, L. infantum lipids could eventually interfere with $\alpha$-GalCer presentation and iNKT cell activation by binding to an external site of the CD1d molecule.

In conclusion, we provide evidence that L. infantum exoproducts impair TCR-dependent human iNKT cell expansion and modulate their immune responses. Our results support the conclusion that L. infantum Exo, EV, and VDE fractions should be considered as parasite virulence factors that can downregulate protective immunity. Therefore, a better understanding of their contribution to Leishmania infection spread and of the regulatory functions of iNKT cells may lead to advances toward the development of an efficient vaccine design.

\section{ETHICS STATEMENT}

Experiments using PBMCs from healthy donors were performed in accordance with the Helsinki Declaration, with informed written consent received from each donor and managed by each institution [Etablissement Français du Sang (EFS), Paris, France and Immuno-haemotherapy Department of Hospital de São João, Porto, Portugal]. All experiments were approved by the IBMC. INEB (Instituto de Biologia Molecular e Celular-Instituto de Engenharia Biomédica) Animal Ethics Committees and the Portuguese National Authorities for Animal Health guidelines (directive 2010/63/EU). Begoña Pérez-Cabezas and Anabela Cordeiro-da-Silva are accredited for animal research (Portuguese Veterinary Direction, Ministerial Directive 113/2013).

\section{AUTHOR CONTRIBUTIONS}

Conceived and designed the experiments: FM, ML-d-M, and AC-d-S. Performed the experiments: RB, NS, and CP. Analyzed the data: RB, NS, CP, FM, BP-C, ML-d-M, and AC-d-S. Contributed with reagents/materials/analysis tools: FM. Wrote the paper: RB, ML-d-M, and AC-d-S.

\section{ACKNOWLEDGMENTS}

We thank Dr. Elke Schneider for her critical reading of the manuscript. We acknowledge the NIH Tetramer Core Facility (contract HHSN272201300006C) for provision of the CD1d-PBS57

\section{REFERENCES}

1. Chappuis F, Sundar S, Hailu A, Ghalib H, Rijal S, Peeling RW, et al. Visceral leishmaniasis: what are the needs for diagnosis, treatment and control? Nat Rev Microbiol (2007) 5:873-82. doi:10.1038/nrmicro1748

2. Kaye P, Scott P. Leishmaniasis: complexity at the host-pathogen interface. Nat Rev Microbiol (2011) 9:604-15. doi:10.1038/nrmicro2608 tetramers and CD1d monomers, the NCI, USA for providing recombinant human IL-2, and Gennaro De Libero and Lucia Mori (Basel University, Switzerland) for CD1d-transfected C1R cells. We thank Joana Maciel for preparing hEVs.

\section{FUNDING}

This work was supported by Fundação para a Ciência e Tecnologia (FCT)/Ministério da Educação e da Ciência (MEC), cofunded by FEDER under the PT2020 Partnership Agreement through the Research Unit NO. 4293; by European Community's Seventh Framework Programme under grant agreement No. 603182 (Project MuLeVaClin). RB and BP-C were supported by fellowships from the FCT (No. SFRH/BD/88005/2012) and European Community's Seventh Framework Programme Project NMTryPI (No. 603240-2), respectively. We also thank the Investissements d'Avenir programme ANR-2010-MIDI-005, France.

\section{SUPPLEMENTARY MATERIAL}

The Supplementary Material for this article can be found online at http://journal.frontiersin.org/article/10.3389/fimmu.2017.00710/ full\#supplementary-material.

\section{FIGURE S1 | Leishmania infantum Exo, EV, and VDE preparation schema.}

FIGURE S2 | Leishmania infantum Exo, EV, and VDE alone did not modify iNKT cell function. Human iNKT cell lines were incubated with CD1d-transfected C1R cells alone (-) or previously loaded with $\alpha$-GalCer $5 \mathrm{ng} / \mathrm{ml}(+)$ or $L$. infantum Exo, EV, VDE, or hEV. iNKT cell activation was measured by assessing GM-CSF concentration in culture supernatant. Data show means \pm SEM, and the results are representative of two independent experiments $(n=4)$. All groups were tested versus the negative $(-)$ control group $\left({ }^{\star *} p<0.01\right)$

FIGURE S3 | Leishmania infantum Exo, EV, and VDE alone were unable to influence IL-4 and IFN $\gamma$ production by iNKT cells. Histograms represent the percentage of $\mathrm{IL}-4^{+}$(top panel) or IFN $\gamma^{+}$(bottom panel) among iNKT cell line following stimulation by solely CD1d-transfected C1R cells (-) or previously loaded with $\alpha$-GalCer 5 (+) or L. infantum Exo, EV, VDE, or hEV. Data show means \pm SEM, and the results are representative of three independent experiments. All groups were tested versus positive $(-)$ control group $\left.{ }^{\star *} p<0.01\right)$.

FIGURE S4 | Leishmania infantum Exo, EV, and VDE alone failed to inhibit iNKT cell activation in a CD1d dose-dependent manner. (A) Plate-bound mouse CD1d was loaded with a mixture of $\alpha$-GalCer 25 and $100 \mathrm{ng} / \mathrm{ml}$ or L. infantum Exo, EV, VDE, or hEV at distinct doses. 24.8 iNKT cell hybridoma was added, and supernatants were recovered $20 \mathrm{~h}$ later. Data are expressed as means \pm SEM of IL-2 levels detected in culture supernatants. Data are representative of two independent experiments $(n=4)$. All groups were tested versus negative control $(-)$ group $\left({ }^{*} p<0.01\right)$. (B) Representative FACS profile showing the expression of CD1d at the surface of BM-DC previously incubated with $\alpha$-GalCer alone (medium) or associated with $L$. infantum Exo, EV, VDE, or hEV. Data are representative of three independent experiments. 
5. Rodrigues V, Cordeiro-da-Silva A, Laforge M, Silvestre R, Estaquier J. Regulation of immunity during visceral Leishmania infection. Parasit Vectors (2016) 9:118. doi:10.1186/s13071-016-1412-x

6. Santarem N, Racine G, Silvestre R, Cordeiro-da-Silva A, Ouellette M. Exoproteome dynamics in Leishmania infantum. JProteomics (2013) 84: 106-18. doi:10.1016/j.jprot.2013.03.012

7. Silverman JM, Chan SK, Robinson DP, Dwyer DM, Nandan D, Foster LJ, et al. Proteomic analysis of the secretome of Leishmania donovani. Genome Biol (2008) 9:R35. doi:10.1186/gb-2008-9-2-r35

8. Hassani K, Antoniak E, Jardim A, Olivier M. Temperature-induced protein secretion by Leishmania mexicana modulates macrophage signalling and function. PLoS One (2011) 6:e18724. doi:10.1371/journal.pone.0018724

9. Yanez-Mo M, Siljander PR, Andreu Z, Zavec AB, Borras FE, Buzas EI, et al. Biological properties of extracellular vesicles and their physiological functions. J Extracell Vesicles (2015) 4:27066. doi:10.3402/jev.v4.27066

10. Colombo M, Raposo G, Thery C. Biogenesis, secretion, and intercellular interactions of exosomes and other extracellular vesicles. Annu Rev Cell Dev Biol (2014) 30:255-89. doi:10.1146/annurev-cellbio-101512-122326

11. Lo Cicero A, Stahl PD, Raposo G. Extracellular vesicles shuffling intercellular messages: for good or for bad. Curr Opin Cell Biol (2015) 35:69-77. doi:10.1016/ j.ceb.2015.04.013

12. Chaput N, Thery C. Exosomes: immune properties and potential clinical implementations. Semin Immunopathol (2011) 33:419-40. doi:10.1007/s00281010-0233-9

13. Godfrey DI, MacDonald HR, Kronenberg M, Smyth MJ, Van Kaer L. NKT cells: what's in a name? Nat Rev Immunol (2004) 4:231-7. doi:10.1038/ nril309

14. Bendelac A, Savage PB, Teyton L. The biology of NKT cells. Annu Rev Immunol (2007) 25:297-336. doi:10.1146/annurev.immunol.25.022106.141711

15. Brennan PJ, Brigl M, Brenner MB. Invariant natural killer T cells: an innate activation scheme linked to diverse effector functions. Nat Rev Immunol (2013) 13:101-17. doi:10.1038/nri3369

16. Slauenwhite D, Johnston B. Regulation of NKT cell localization in homeostasis and infection. Front Immunol (2015) 6:255. doi:10.3389/fimmu.2015. 00255

17. Kawano T, Cui J, Koezuka Y, Toura I, Kaneko Y, Motoki K, et al. CD1drestricted and TCR-mediated activation of valpha14 NKT cells by glycosylceramides. Science (1997) 278:1626-9. doi:10.1126/science.278.5343.1626

18. Moreira-Teixeira L, Resende M, Devergne O, Herbeuval JP, Hermine O, Schneider E, et al. Rapamycin combined with TGF-beta converts human invariant NKT cells into suppressive Foxp3+ regulatory cells. J Immunol (2012) 188:624-31. doi:10.4049/jimmunol.1102281

19. Moreira-Teixeira L, Resende M, Coffre M, Devergne O, Herbeuval JP, Hermine O, et al. Proinflammatory environment dictates the IL-17-producing capacity of human invariant NKT cells. JImmunol (2011) 186:5758-65. doi:10.4049/jimmunol.1003043

20. Michel ML, Mendes-da-Cruz D, Keller AC, Lochner M, Schneider E, Dy M, et al. Critical role of ROR-gammat in a new thymic pathway leading to IL-17-producing invariant NKT cell differentiation. Proc Natl Acad Sci U S A (2008) 105:19845-50. doi:10.1073/pnas.0806472105

21. Macho-Fernandez E, Brigl M. The extended family of CD1d-restricted NKT cells: sifting through a mixed bag of TCRs, antigens, and functions. Front Immunol (2015) 6:362. doi:10.3389/fimmu.2015.00362

22. Tupin E, Kinjo Y, Kronenberg M. The unique role of natural killer $\mathrm{T}$ cells in the response to microorganisms. Nat Rev Microbiol (2007) 5:405-17. doi:10.1038/nrmicro1657

23. Berzins SP, Smyth MJ, Baxter AG. Presumed guilty: natural killer T cell defects and human disease. Nat Rev Immunol (2011) 11:131-42. doi:10.1038/ nri2904

24. Michel ML, Keller AC, Paget C, Fujio M, Trottein F, Savage PB, et al. Identification of an IL-17-producing NK1.1(neg) iNKT cell population involved in airway neutrophilia. J Exp Med (2007) 204:995-1001. doi:10.1084/ jem.20061551

25. Van Kaer L, Parekh VV, Wu L. The response of CD1d-restricted invariant NKT cells to microbial pathogens and their products. Front Immunol (2015) 6:226. doi:10.3389/fimmu. 2015.00226

26. Zajonc DM, Girardi E. Recognition of microbial glycolipids by natural killer T cells. Front Immunol (2015) 6:400. doi:10.3389/fimmu.2015.00400
27. Campos-Martin Y, Colmenares M, Gozalbo-Lopez B, Lopez-Nunez M, Savage PB, Martinez-Naves E. Immature human dendritic cells infected with Leishmania infantum are resistant to NK-mediated cytolysis but are efficiently recognized by NKT cells. J Immunol (2006) 176:6172-9. doi:10.4049/ jimmunol.176.10.6172

28. Karmakar S, Bhaumik SK, Paul J, De T. TLR4 and NKT cell synergy in immunotherapy against visceral leishmaniasis. PLoS Pathog (2012) 8:e1002646. doi:10.1371/journal.ppat.1002646

29. Sharif S, Arreaza GA, Zucker P, Mi QS, Sondhi J, Naidenko OV, et al. Activation of natural killer $\mathrm{T}$ cells by alpha-galactosylceramide treatment prevents the onset and recurrence of autoimmune Type 1 diabetes. Nat Med (2001) 7:1057-62. doi:10.1038/nm0901-1057

30. Geissmann F, Cameron TO, Sidobre S, Manlongat N, Kronenberg M, Briskin MJ, et al. Intravascular immune surveillance by CXCR6+ NKT cells patrolling liver sinusoids. PLoS Biol (2005) 3:e113. doi:10.1371/journal.pbio. 0030113

31. Hill TM, Gilchuk P, Cicek BB, Osina MA, Boyd KL, Durrant DM, et al. Border patrol gone awry: lung NKT cell activation by Francisella tularensis exacerbates tularemia-like disease. PLoS Pathog (2015) 11:e1004975. doi:10.1371/ journal.ppat.1004975

32. Santarem N, Cunha J, Silvestre R, Silva C, Moreira D, Ouellette M, et al. The impact of distinct culture media in Leishmania infantum biology and infectivity. Parasitology (2014) 141:192-205. doi:10.1017/ S0031182013001388

33. Geddings JE, Hisada Y, Boulaftali Y, Getz TM, Whelihan M, Fuentes R, et al. Tissue factor-positive tumor microvesicles activate platelets and enhance thrombosis in mice. J Thromb Haemost (2016) 14:153-66. doi:10.1111/ jth. 13181

34. Resende M, Moreira D, Augusto J, Cunha J, Neves B, Cruz MT, et al. Leishmania-infected MHC class IIhigh dendritic cells polarize CD4+ T cells toward a nonprotective T-bet+ IFN-gamma+ IL-10+ phenotype. J Immunol (2013) 191:262-73. doi:10.4049/jimmunol.1203518

35. Kinjo Y, Tupin E, Wu D, Fujio M, Garcia-Navarro R, Benhnia MR, et al. Natural killer T cells recognize diacylglycerol antigens from pathogenic bacteria. Nat Immunol (2006) 7:978-86. doi:10.1038/ni1380

36. Song W, van der Vliet HJ, Tai YT, Prabhala R, Wang R, Podar K, et al. Generation of antitumor invariant natural killer $\mathrm{T}$ cell lines in multiple myeloma and promotion of their functions via lenalidomide: a strategy for immunotherapy. Clin Cancer Res (2008) 14:6955-62. doi:10.1158/1078-0432. CCR-07-5290

37. Bligh EG, Dyer WJ. A rapid method of total lipid extraction and purification. Can J Biochem Physiol (1959) 37:911-7. doi:10.1139/059-099

38. Stanley AC, Zhou Y, Amante FH, Randall LM, Haque A, Pellicci DG, et al. Activation of invariant NKT cells exacerbates experimental visceral leishmaniasis. PLoS Pathog (2008) 4:e1000028. doi:10.1371/journal.ppat.1000028

39. Amprey JL, Im JS, Turco SJ, Murray HW, Illarionov PA, Besra GS, et al. A subset of liver NK T cells is activated during Leishmania donovani infection by CD1d-bound lipophosphoglycan. J Exp Med (2004) 200:895-904. doi:10.1084/jem.20040704

40. Yu ED, Girardi E, Wang J, Mac TT, Yu KO, Van Calenbergh S, et al. Structural basis for the recognition of C20:2-alphaGalCer by the invariant natural killer T cell receptor-like antibody L363. J Biol Chem (2012) 287:1269-78. doi:10.1074/ jbc.M111.308783

41. Ferguson MA. The structure, biosynthesis and functions of glycosylphosphatidylinositol anchors, and the contributions of trypanosome research. J Cell Sci (1999) 112(Pt 17):2799-809.

42. Szempruch AJ, Dennison L, Kieft R, Harrington JM, Hajduk SL. Sending a message: extracellular vesicles of pathogenic protozoan parasites. Nat Rev Microbiol (2016) 14:669-75. doi:10.1038/nrmicro.2016.110

43. Atayde VD, Aslan H, Townsend S, Hassani K, Kamhawi S, Olivier M. Exosome secretion by the parasitic protozoan Leishmania within the sand fly midgut. Cell Rep (2015) 13:957-67. doi:10.1016/j.celrep.2015.09.058

44. Halle M, Gomez MA, Stuible M, Shimizu H, McMaster WR, Olivier M, et al. The Leishmania surface protease GP63 cleaves multiple intracellular proteins and actively participates in p38 mitogen-activated protein kinase inactivation. J Biol Chem (2009) 284:6893-908. doi:10.1074/jbc.M805861200

45. Silverman JM, Clos J, Horakova E, Wang AY, Wiesgigl M, Kelly I, et al. Leishmania exosomes modulate innate and adaptive immune responses 
through effects on monocytes and dendritic cells. JImmunol (2010) 185: 5011-22. doi:10.4049/jimmunol.1000541

46. Rossjohn J, Pellicci DG, Patel O, Gapin L, Godfrey DI. Recognition of CD1d-restricted antigens by natural killer T cells. Nat Rev Immunol (2012) 12:845-57. doi:10.1038/nri3328

47. Kinjo Y, Wu D, Kim G, Xing GW, Poles MA, Ho DD, et al. Recognition of bacterial glycosphingolipids by natural killer T cells. Nature (2005) 434:520-5. doi:10.1038/nature 03407

48. Kinjo Y, Illarionov P, Vela JL, Pei B, Girardi E, Li X, et al. Invariant natural killer $\mathrm{T}$ cells recognize glycolipids from pathogenic Gram-positive bacteria. Nat Immunol (2011) 12:966-74. doi:10.1038/ni.2096

49. Zamora-Chimal J, Hernandez-Ruiz J, Becker I. NKT cells in leishmaniasis. Immunobiology (2017) 222:641-6. doi:10.1016/j.imbio.2016.11.014

50. Leite-De-Moraes MC, Hameg A, Arnould A, Machavoine F, Koezuka Y, Schneider E, et al. A distinct IL-18-induced pathway to fully activate NK T lymphocytes independently from TCR engagement. J Immunol (1999) 163:5871-6.

51. Karmakar S, Paul J, De T. Leishmania donovani glycosphingolipid facilitates antigen presentation by inducing relocation of CD1d into lipid rafts in infected macrophages. Eur J Immunol (2011) 41:1376-87. doi:10.1002/ eji.201040981

52. Pereira CS, Sa-Miranda C, De Libero G, Mori L, Macedo MF. Globotriaosylceramide inhibits iNKT-cell activation in a CD1d-dependent manner. Eur J Immunol (2016) 46:147-53. doi:10.1002/eji.201545725
53. Pereira CS, Macedo MF. CD1-restricted T cells at the crossroad of innate and adaptive immunity. J Immunol Res (2016) 2016:2876275. doi:10.1155/ 2016/2876275

54. Schofield L, McConville MJ, Hansen D, Campbell AS, Fraser-Reid B, Grusby MJ, et al. CD1d-restricted immunoglobulin G formation to GPIanchored antigens mediated by NKT cells. Science (1999) 283:225-9. doi:10.1126/science.283.5399.225

55. Assis RR, Ibraim IC, Noronha FS, Turco SJ, Soares RP. Glycoinositolphospholipids from Leishmania braziliensis and L. infantum: modulation of innate immune system and variations in carbohydrate structure. PLoS Negl Trop Dis (2012) 6:e1543. doi:10.1371/journal.pntd.0001543

Conflict of Interest Statement: The authors declare that the research was conducted in the absence of any commercial or financial relationships that could be construed as a potential conflict of interest.

Copyright $₫ 2017$ Belo, Santarém, Pereira, Pérez-Cabezas, Macedo, Leite-de-Moraes and Cordeiro-da-Silva. This is an open-access article distributed under the terms of the Creative Commons Attribution License (CC BY). The use, distribution or reproduction in other forums is permitted, provided the original author(s) or licensor are credited and that the original publication in this journal is cited, in accordance with accepted academic practice. No use, distribution or reproduction is permitted which does not comply with these terms. 